\title{
Solar Flat Plate Collector Performance By Variation of Different Parameters
}

\author{
Sunil.K.Amrutkar ${ }^{1}$, Satyshree Ghodke ${ }^{2}$, Dr. K. N. Patil ${ }^{3}$ \\ ${ }^{1}$ Mechanical Department, TIT, R.G.P.V. Bhopal India \\ ${ }^{2}$ Mechanical Department, TIT, R.G.P.V. Bhopal India \\ ${ }^{3}$ Mechanical Department, IIT, Mumbai India
}

\begin{abstract}
The flat plate collector is one of the most widely used device for harnessing the solar energy. The measurement of the flat plate collector performance is the collector efficiency. The collector efficiency is the ratio of the useful energy gain to the incident solar energy over a particular period of time. The useful energy gain in turn depends on the energy loss from the top surface of the collector both due to convective $\&$ radiative heat transfer processes. The losses from the bottom and from the edges of the collector do exist but their contribution is not as significant as the losses from the top. Hence investigations are carried out to study the losses by changing the collector tilt to determine the top loss coefficient.
\end{abstract}

Keywords -Collector, Useful Heat Gain, Losses, Top loss coefficient, Efficiency.

\section{INTRODUCTION}

The technology of harnessing the solar energy has reached to the state of commercialization on mass scale. The greatest advantage of using solar energy is that it is an inexhaustible and pollution free source of energy. The Lord Sun gives approximately $1.8 \times 1011$ MW powers, which is many thousand times higher than the present consumption rate on earth. This makes it one of the most promising of the Unconventional sources of energy.

\section{NOMENCLATURE}

$\mathrm{A}_{\mathrm{p}} \quad$ Area of absorber plate, $\mathrm{m}^{2}$

$\mathrm{Q}_{\mathrm{s}} \quad$ Losses of heat from sides, $\mathrm{W}$

$\mathrm{Q}_{\mathrm{b}}$ Losses of heat from bottom, $\mathrm{W}$

$\mathrm{Q}_{\mathrm{t}} \quad$ Losses of heat from top, $\mathrm{W}$

$\mathrm{E}_{\text {in }}$ Energy input, $\mathrm{W}$

$\beta$ Collector tilt angle, degrees

$\mathrm{N}$ No. of covers

$\sigma$ Stefan Boltzmann constant $5.67 \times 10^{-8} \mathrm{~W} / \mathrm{m}^{2} \mathrm{~K}^{-4}$

$\varepsilon_{\mathrm{p}}$ Emissivity of plate

$\varepsilon_{\mathrm{c}}$ Emissivity of cover

$\mathrm{T}_{\mathrm{b}}$ Temperature of bottom cover of collector, $\mathrm{K}$

$\mathrm{T}_{\mathrm{c} 1}$ Mean temperature of $1^{\text {st }}$ cover, $\mathrm{K}$

$\mathrm{T}_{\mathrm{c} 2}$ Mean temperature of $2^{\text {nd }}$ cover

$\mathrm{T}_{\mathrm{c}}$ Thickness of cover, $\mathrm{m}$

$\mathrm{U}_{\mathrm{t}}$ Top heat loss co-efficient, $\mathrm{W} / \mathrm{m}^{2} \mathrm{~K}$

$\mathrm{U}_{\mathrm{L}}$ Over all heat loss co-efficient of collector, $\mathrm{W} / \mathrm{m}^{2} \mathrm{~K}$

$\mathrm{T}_{\mathrm{h}}$ Temperature of heater plate, $\mathrm{K}$

$\mathrm{T}_{\mathrm{p}}$ Temperature of absorber plate, $\mathrm{K}$

$\mathrm{h}_{\mathrm{w}}$ wind induced convective heat transfer co-efficient, W/ $\mathrm{m}^{2} \mathrm{~K}$

$\mathrm{h}_{\mathrm{Cl-2}}$ Convective heat transfer co-efficient between $1^{\text {st }}$ and $2^{\text {nd }}$ cover, $\mathrm{W} / \mathrm{m}^{2} \mathrm{~K}$

$\mathrm{K}_{\mathrm{c}}$ Thermal conductivity of cover, W/m $/ \mathrm{m}^{2} \mathrm{~K}$ $\mathrm{h}_{\mathrm{p}-\mathrm{c}}$ Convective heat transfer co-efficient between absorber plate \& cover, $\mathrm{W} / \mathrm{m}^{2} \mathrm{~K}$

$\mathrm{h}_{\mathrm{c}-\mathrm{a}}$ Convective heat transfer co-efficient between cover \&atmosphere, $\mathrm{W} / \mathrm{m}^{2} \mathrm{~K}$

$\mathrm{F}_{\mathrm{p}-\mathrm{c}}$ Radiation shape factor between plate \& cover

$\varepsilon_{\mathrm{g}}$ Emissivity of glass cover

$\mathrm{Q}_{\mathrm{u}}$ Useful energy gain, $\mathrm{W}$

$\mathrm{S}$ Flux absorbed by collector, W/ $\mathrm{m}^{2}$

\section{FLAT PLATE COLLECTOR}

$\mathrm{T}$ he flat plate collector shown in Fig. 1 is one of the most widely used device for harnessing solar energy. In any solar collection device, the principle usually followed is to expose a dark surface to solar radiation so that the radiation is absorbed. A part of the absorbed radiation is then transferred to a fluid like air or water. When no optical concentration is done; the device in which the collection is achieved is called the flat plate collector. The flat plate collector is the most important type of solar collector because it is simple in design, has no moving parts and requires little maintenance. It can be used for a variety of applications in which temperature ranging from $40{ }^{\circ} \mathrm{C}$ to $100^{\circ} \mathrm{C}$ is required.

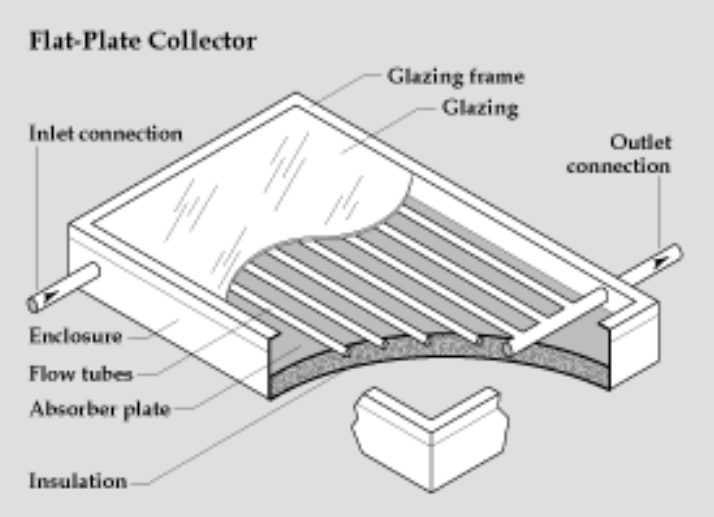

Fig. 1 Solar flat plate collector

\section{PERFORMANCE ANALYSIS OF FLAT PLATE COLLECTOR}

An energy balance on the absorber plate yields the following equation for steady state:

$$
\mathrm{q}_{\mathrm{u}}=\mathrm{A}_{\mathrm{p}} \mathrm{S}-\mathrm{q}_{\mathrm{l}}
$$

where, $\mathrm{q}_{\mathrm{u}}=$ useful heat gain, i.e., the rate of heat transfer to the working fluid; $S=$ incident solar flux absorbed in the absorber plate; $A_{p}=$ area of the absorber plate and

$\mathrm{q}_{1}=$ rate of heat loss. by the absorber. In order to determine the flux ' $S$ ' absorbed by the absorber a term called the transmitivity absorptivity product $\left({ }_{\tau \alpha}\right)$ which is defined as the 


\section{Sunil.K.Amrutkar, Satyshree Ghodke, Dr. K. N. Patil / IOSR Journal of Engineering (IOSRJEN) www.iosrjen.org \\ ISSN : 2250-3021}

Vol. 2 Issue 2, feb.2012, pp. 369-371

ratio of the flux absorbed in the absorber plate to the flux incident on the cover system, is evaluated and is given by ' $\mathrm{S}$ '.

$$
S=I_{b} r_{b}(\tau \alpha)+I_{d} r_{d}+\left(I_{b}+I_{d}\right) r_{r}
$$

Where

$\tau=$ transmitivity of glass cover system.

$\alpha=$ absorptivity of absorber plate.

$(\tau \alpha) \mathrm{b}=$ transmitivity absorptivity product for the beam radiation falling on the collector.

${ }_{(\tau \alpha) \mathrm{d}}=$ transmitivity absorptivity product for the diffuse radiation falling on the collector.

Now, rate of the heat loss is given by,

$q_{l}=U_{l} A_{p}\left(T_{p m}-T_{a}\right)$

Where,

$\mathrm{U}_{1}$ = overall loss coefficient

$\mathrm{A}_{\mathrm{p}}=$ area of absorber plate.

$\mathrm{T}_{\mathrm{pm}}=$ average temperature of the absorber plate, and

$\mathrm{T}_{\mathrm{a}}=$ temperature of surrounding air.

The heat loss from the collector is the sum of the heat loss from the top, the bottom and the sides.

$q_{l}=q_{t}+q_{b}+q_{s}$

Where,

$q_{t}=U_{t} A_{p}\left(T_{p m}-T_{a}\right)$

$q_{s}=U_{s} A_{p}\left(T_{p m}-T_{a}\right)$

$q_{b}=U_{b} A_{p}\left(T_{p m}-T_{a}\right)$

$U_{l}=U_{t}+U_{b}+U_{s}$

Here, $\mathrm{U}_{\mathrm{t}}, \mathrm{U}_{\mathrm{b}}$ and $\mathrm{U}_{\mathrm{s}}$ are the top, the bottom and the side loss co-efficient respectively.

\section{TOP LOSS COEFFICIENT}

The top loss co-efficient Ut is evaluated by considering the convection and the radiation loss from the absorber plate in the upward direction. For the purpose of calculation, it is assumed that

1) The transparent covers and the absorber plate constitute a system of infinite parallel surface and flow of the heat is one dimensional and steady.

2) Temperature across the thickness of the cover is negligible and that the interaction between the incoming solar radiation absorbed by the covers and the outgoing loss may be neglected

A schematic diagram of two-cover system is shown in the Fig.

2 .

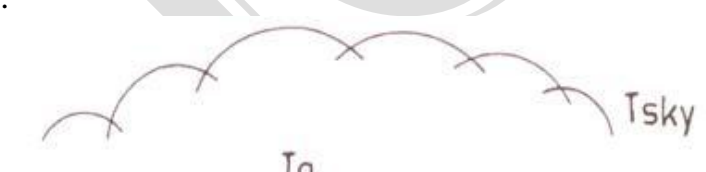

Ta
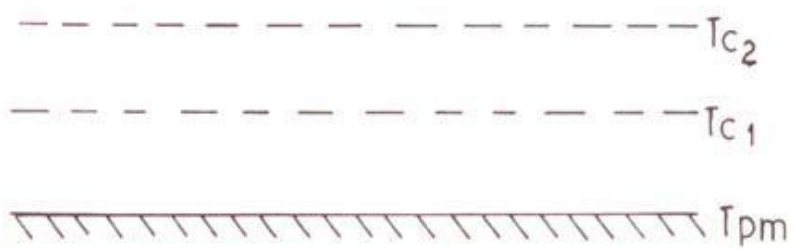

Fig. 2 schematic diagram of two-cover system
In steady state the heat is transferred by convection and radiation between the following:

1) The absorber plate and the first cover.

2) The first cover and the second cover and

3) The second cover and the surrounding must be equal.

$$
\begin{aligned}
& \frac{q_{t}}{A_{p}}=h_{p c}-c_{1}\left(T_{p m}-T_{c 1}\right)+\frac{\sigma\left(T_{p m}^{4}-T^{4}{ }_{c 1}\right)}{\left(\frac{1}{\varepsilon_{p}}+\frac{1}{\varepsilon_{c}}-1\right)} \\
& \frac{q_{t}}{A_{p}}=h_{p}-c 2\left(T_{c 1}-T_{c 2}\right)+\frac{\sigma\left(T^{4}{ }_{c 1}-T^{4}{ }_{c 2}\right)}{\left(\frac{1}{\varepsilon_{p}}+\frac{1}{\varepsilon_{c}}-1\right)} \\
& \frac{q_{t}}{A_{p}}=h w\left(T_{c 2}-T_{a}\right)+\sigma \varepsilon_{c}\left(T_{c 2}^{4}-T_{s k y}^{4}\right)
\end{aligned}
$$

Equations 9 to 11 constitute a set of three nonlinear equations, which can be solved iteratively by assuming $\mathrm{T}_{\mathrm{c} 1}$ and $\mathrm{T}_{\mathrm{c} 2}$ for which $q_{t} / A_{p}$ is same by all these equations. There exists few correlations for calculating $h_{p-c}$, hw, and $U_{t}$ which have been derived based on different experiments and techniques which may not be representative of real life collector. The present work is an attempt to present the comparative assessment of these correlations, based on systematic experiments, on an experimental research collector which is a representative of real life collector and to study the effect of collector tilt angle on top losses and top loss co-efficient.

\section{EXPERIMENTAL DETERMINATION OF VARIOUS PARAMETERS}

Once the steady state is achieved the top loss, the overall loss and the convective heat transfer coefficients are evaluated from the energy balance equation as follows:

$\mathrm{Qu}=\mathrm{Q}_{\mathrm{t}}+\mathrm{Q}_{\mathrm{b}}+\mathrm{Q}_{\mathrm{s}}+\mathrm{Q}_{\mathrm{c}}+\mathrm{Q}_{\mathrm{e}}+\mathrm{Q}_{\mathrm{sl}}$

$\mathrm{Qu}$ is the total energy supplied to the heaters which is same as the heat losses from collector under steady state. The bottom losses, $\mathrm{Q}_{\mathrm{b}}$, side losses, $\mathrm{Q}_{\mathrm{s}}$, edge losses, $\mathrm{Q}_{\mathrm{e}}$, corner losses, $\mathrm{Q}_{\mathrm{c} .}$ Sealing losses are assumed as $1 \%$ and hence top losses are calculated by subtracting all these losses from input energy $\mathrm{Q}_{\mathrm{u}}$. Once $\mathrm{Q}_{\mathrm{t}}$ is obtained $\mathrm{U}_{1}, \mathrm{U}_{\mathrm{t}}, \mathrm{h}_{\mathrm{p}-\mathrm{c}}$ and hw may be evaluated as follows:

$$
\begin{aligned}
& U_{t}=\frac{Q_{i n}}{A_{p}}\left(T_{p}-T_{a}\right) \\
& U_{t}=\frac{Q_{t}}{A_{p}}\left(T_{p}-T_{a}\right) \\
& \frac{q_{t}}{A_{p}}=h_{p c}-c_{1}\left(T_{p m}-T_{c 1}\right)+\frac{\sigma\left(T^{4}{ }_{p m}-T^{4}{ }_{c 1}\right)}{\left(\frac{1}{\varepsilon_{p}}+\frac{1}{\varepsilon_{c}}-1\right)}
\end{aligned}
$$


Vol. 2 Issue 2, feb.2012, pp. 369-371

$$
\begin{aligned}
& h_{p c}-c_{1}=\frac{q_{t}}{A_{p}\left(T_{p m}-T_{c 1}\right)}-\frac{\sigma\left(T_{p m}^{4}-T_{c 1}^{4}\right)}{\left(\frac{1}{\varepsilon_{p}}+\frac{1}{\varepsilon_{c}}-1\right)\left(T_{p m}-T_{c 1}\right)} \\
& \left.h w=\frac{q_{t}}{A_{p}\left(T_{c 2}-T_{a}\right)}-\frac{\sigma \varepsilon_{c}\left(T^{4}{ }_{c 2}-T^{4}{ }_{s k y}\right)}{T_{c 2}-T_{a}}\right)
\end{aligned}
$$

\section{RESULT AND DISCUSSION}

Fig.2(a) it is seen that the values of the useful heat gain and efficiency increase sharply from 0900 to1100 hour touch a peak around noon and then drop sharply after 1500 hour .the variation obtained is typical for flat plate collector and indicates the strong dependence of these factors on the radiation incident on the collector.Fig.2(b) It is also seen that the value of the top loss coefficient vary with useful heat gain during the day hours, as noon increase the $U_{t}, Q_{u}$ also increases. Fig.2(c) it is observed that effect of absorber plate temperature on top loss coefficients for days hours and peak around noon $\mathrm{U}_{\mathrm{t}}$ and $\mathrm{T}_{\mathrm{pm}}$ also maximum. Efficiency over the whole period, during which useful energy is collected efficiency and solar radiation are valid of an hour, the efficiency average over 10 hours from 0830 to1630h works out to be 39.6 percent.

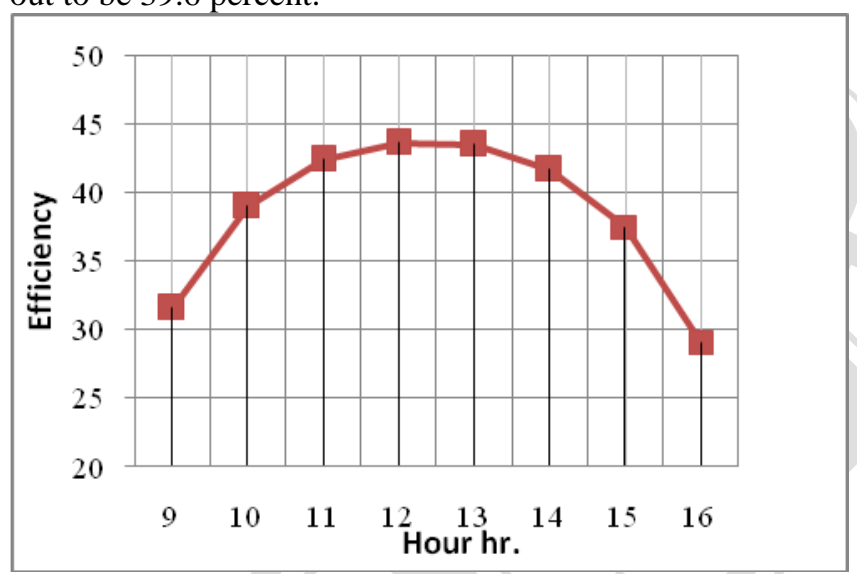

Fig.2 (a) variation of efficiency of a collector with day hours.

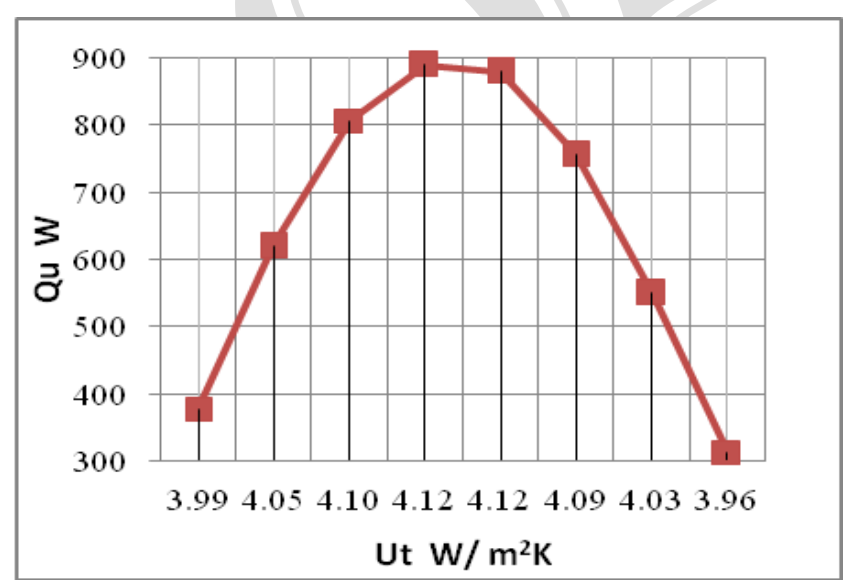

Fig.2(b) top loss coefficients versus heat gain during the day hours.

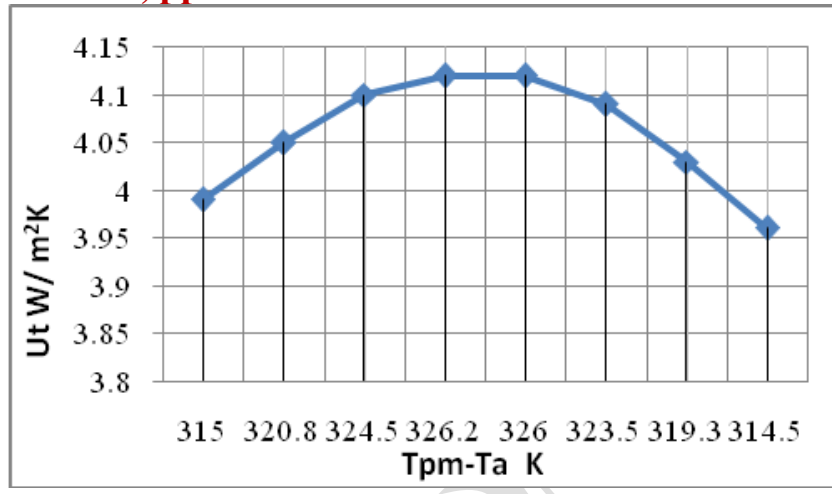

Fig.2(c) effect of absorber plate temperature on top loss coefficients

\section{CONCLUSION}

Efficiency over the whole period, during which useful energy is collected the efficiency average over 10 hours from 0830 to1630h works out to be 39.6 percent. The increase in efficiency $\mathrm{Q}_{\mathrm{u}} \mathrm{U}_{\mathrm{t}}$ and $\mathrm{T}_{\mathrm{pm}}$, at peak hour of noon and then drop sharply after 1500 hour.

\section{III.REFERENCES}

[1] J. A. Duffie and W. A. Beckman, "Solar Engineering of Thermal Processes", 2nd Ed: John Willey and Sons, Inc., New York, 1991.

[2] Sukhatme, S.P., "Solar Energy-Principle of Thermal Collection and Storage", Tata McGraw Hill Pub, Co., Delhi, 1984.

[3] Hottel HC, Woertz BB. 1942. The performance of flatplate solar heat collectors. Trans ASME. 64: 94-102

[4] Mullick, S.c. and Samdarshi, S.K., "Analytical Equation For The TopHeat Loss Factor of A Flat Plate Collector With Double Glazing", ASME Journal of Solar Energy Engineering, Vol. 113, pp. 117·122, May 1991

[5] Rabl, A" "Active Solar Collectors and Their Applications", Oxford Univ. Press. 1985.

[6] Malhotra, A., Garg, H.P. and Palit, A., "Heat loss Calculation of Flat Plate Solar Collector". J. Thermal Engineering, Vol. 2; No.2... pp. 59-62,1981.

[7] M. K. Bhatt, S. N. Gaderia and S. A. Channiwala Distribution of Heat Losses in a Single Glazed Flat Plate Collector at Variable Wind velocity - An Experimental Simulation.

[8] V. K. Agarwal and D. C. Larson, "Calculation of The Top Loss Coefficient of A Flat Plate Collector", Solar Energy, Vol. 27, 1981, pp.69-71 